\title{
Article \\ Case-Based Reasoning for Hidden Property Analysis of Judgment Debtors
}

\author{
Huirong Zhang ${ }^{1}$, Zhenyu Zhang ${ }^{2}$, Lixin Zhou ${ }^{3, *}$ and Shuangsheng $\mathrm{Wu}^{4}$ \\ 1 School of Labor Relationship, Shandong Management University, Jinan 250357, China; \\ 14438120140358@sdmu.edu.cn \\ 2 School of Automation, Nanjing University of Science and Technology, Nanjing 210094, China; \\ zhangzhenyu@njust.edu.cn \\ 3 Business School, University of Shanghai for Science and Technology, Shanghai 200093, China \\ 4 School of Economics and Management, Tongji University, Shanghai 200092, China; wss0810@tongji.edu.cn \\ * Correspondence: zhoulixin1861@hotmail.com
}

Citation: Zhang, H.; Zhang, Z.;

Zhou, L.; Wu, S. Case-Based

Reasoning for Hidden Property Analysis of Judgment Debtors.

Mathematics 2021, 9, 1559. https://

doi.org/10.3390/math9131559

Academic Editors: Hsien-Chung Wu and Vassilis C. Gerogiannis

Received: 18 May 2021

Accepted: 1 July 2021

Published: 2 July 2021

Publisher's Note: MDPI stays neutral with regard to jurisdictional claims in published maps and institutional affiliations.

Copyright: (c) 2021 by the authors. Licensee MDPI, Basel, Switzerland. This article is an open access article distributed under the terms and conditions of the Creative Commons Attribution (CC BY) license (https:/ / creativecommons.org/licenses/by/ $4.0 /)$.

\begin{abstract}
Many judgment debtors try to evade, confront, and delay law enforcement using concealing and transferring their property to resist law enforcement in China. The act of hiding property seriously affects people's legitimate rights and interests and China's legal authority. Therefore, it is essential to find an effective method of analyzing whether a judgment debtor hides property. Aiming at the hidden property analysis problem, we propose a case-based reasoning method for the judgment debtor's hidden property analysis. In the hidden property analysis process, we present the attributes of the enforcement case by crisp symbols, crisp numbers, interval numbers, and fuzzy linguistic variables and develop a hybrid similarity measure between the historical enforcement case and the target enforcement case. The results show that the recommendations obtained with the information and knowledge of similar historical cases are consistent with judicial practice, which can reduce the work pressure of law enforcement officers and improve the efficiency of handling enforcement cases.
\end{abstract}

Keywords: law enforcement; case-based reasoning (CBR); similarity measure; hidden property; judgment debtor

\section{Introduction}

Due to the influence of the whole society's low legal consciousness, lack of the social credit system, imperfections of the property supervision system, and other factors, a large number of judgment debtors try their best to evade, confront, and delay law enforcement by concealing and transferring their property and even resort to violent means to resist law enforcement. In China, valid legal instruments are difficult to implement, and we call it "difficulty in law enforcement." The problem of "difficulty in law enforcement" seriously affects the realization of people's legitimate rights and interests and promotes credibility and power of China's justice. Moreover, the Supreme People's Court's statistical data show that from 2016 to 2018, there were about six million enforcement cases per year on average, and every law enforcement officer needed to handle about 150 enforcement cases every year. The existing staffing is far from meeting the needs of judicial enforcement. Therefore, it is essential to study an effective method to analyze whether a judgment debtor hides property, which improves the efficiency of enforcement cases and reduces law enforcement costs.

The decision whether hidden property analysis of a judgment debtor is needed mainly relies on the law enforcement officers' own case handling experience to judge whether the judgment debtor has concealed property. Still, the process of handling cases is often restricted by subjective and objective factors such as information asymmetry and personal prejudice. Besides, hidden property analysis information comes from the Supreme People's 
Court's inspection and control system. The system is connected with the Ministry of Public Security, the Ministry of Transport, the People's Bank of China, and banking financial institutions. It can include the real estate, deposits, ships, vehicles, and other judgment debtor information. It can cover the main property forms and relevant information on the judgment debtor. The existing inspection and control system involves various data forms, such as crisp symbols, crisp numbers, interval numbers, and fuzzy variables. For example, the gender of the judgment debtor is male or female, expressed as a crisp symbol, and the annual income is a crisp number. When describing the value of the attribute "frozen property," it is impossible to accurately estimate the exact amount of frozen property such as houses and vehicles according to the market value. Generally, an interval value is more reasonable than describing the attribute by a crisp number. Meanwhile, considering there are no unified quantitative methods to express attributes such as credibility, consumption level, and work, fuzzy linguistic variables provide a suitable tool for presenting the attribute values given by expert judges. Thus, fuzzy logic is implemented to express the imprecision and vagueness of the enforcement cases' attributes.

The existing method of hidden property analysis has four aspects of characteristics and is shown as follows. Firstly, there is no unified and feasible method to facilitate the operation in the decision-making process of enforcement cases; it mainly depends on the law enforcement officers' experience to deal with enforcement cases. Secondly, law enforcement officers are under high pressure and have to deal with many enforcement cases. Therefore, there is no effective analysis method to preliminarily judge the possibility of concealment of the judgment debtor's property. It is impossible to find out the hidden property of a judgment debtor. Thirdly, the existing inspection and control system involves various forms of data, such as text data, crisp symbols, crisp numbers, interval numbers, and fuzzy variables. Fourthly, it mainly depends on the law enforcement officers to screen the data, which need to be processed quantitatively.

We developed a case-based reasoning (CBR) approach to hidden property analysis of a judgment debtor through the above analysis. CBR is a methodology that imitates the reasoning and thinking process of human beings. It mainly uses specific knowledge of historical cases to solve new problems by searching for historical cases similar to new problems, which provides a useful technology for analyzing the possibility of property hidden by a judgment debtor. The main idea of the CBR approach to hidden property analysis is to extract the experience of historical enforcement cases to analyze whether the judgment debtor has concealed property or not. Specifically, the significant attributes of the historical enforcement case and the target enforcement case, such as credibility and consumption level, are presented. Then, the hybrid similarity between the historical enforcement case and the target enforcement case are calculated. Moreover, the hybrid similarity is used to extract several similar historical enforcement cases with reference significance for the target enforcement case. The historical case set's empirical knowledge helps to analyze and assess whether the judgment debtor conceals property in the target enforcement case. The case reasoning process is shown in Figure 1.

The contributions of our work are as follows. Firstly, we develop the framework of CBR-based hidden property analysis of a judgment debtor which provides a fast and useful tool to analyze the possibility of the property concealed by a judgment debtor. It solves the decision-making problem of the target enforcement case according to the experience of historical cases, assists law enforcement officers in finding out the hidden property of judgment debtors, and improves the accuracy and efficiency of the enforcement cases' judgments. Secondly, in the enforcement case presentation process, we use four types of data transformed from the Supreme People's Court's inspection and control system: crisp symbols, crisp numbers, interval numbers, and fuzzy linguistic variables. Thirdly, we propose a hybrid similarity measure method including the four types of data, which is simple and effective. Finally, we give the optimal recommendations for hidden property analysis, including the four types of data in CBR, not just case retrieval. 


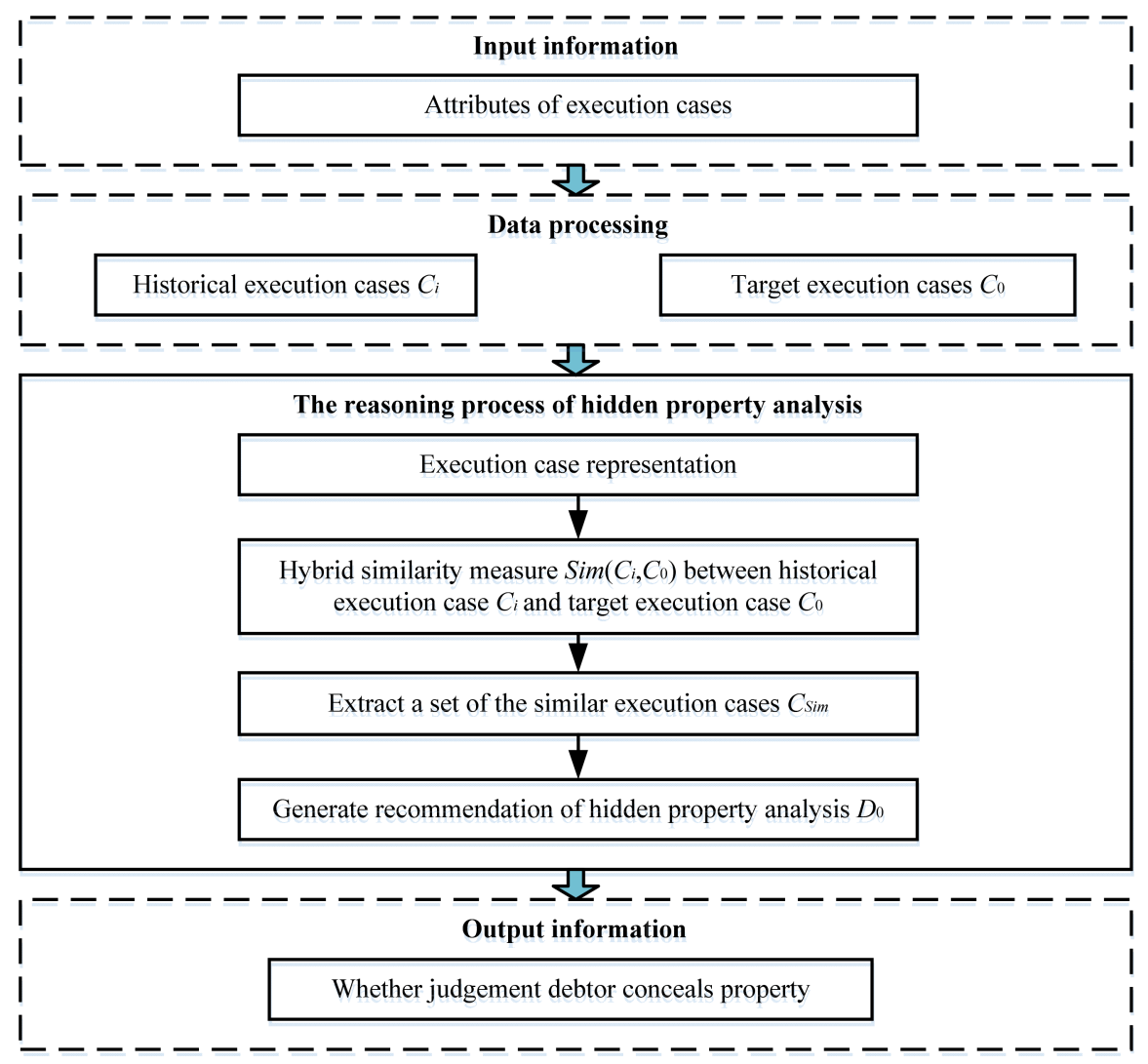

Figure 1. Flowchart of CBR for hidden property analysis of judgment debtors.

The rest of our work is constructed as follows. Section 2 reviews some related literature about hidden property analysis and CBR. Section 3 develops a CBR model for hidden property analysis of a judgment debtor. The framework of the CBR-based model for hidden property analysis, enforcement case presentation, a measure of hybrid similarity between a historical case and the target case, extraction of similar historical cases, and generation of recommendations are introduced. Section 4 provides a case study concerning hidden property analysis of a judgment debtor. Some conclusions are presented in Section 5.

\section{Literature Review}

At present, China is still in the primary stage of socialism. There are some problems, such as weak awareness of the rule of law, lack of social integrity, severe lag in the implementation of the legal system, laws and regulations, resulting in the phenomenon of "difficulty in law enforcement." The problem of "difficulty in law enforcement" seriously affects the social harmony and stability, the fairness and justice of the law, and the authority of justice, which the society is widely concerned about. Hidden property analysis of a judgment debtor acts as an essential link to solve the problem of "difficulty in law enforcement."

Scholars have been paying more attention to the use of computers and information technology to detect fraud and money laundering of criminal suspects. Bell [1] analyzed and summarized the cases of concealment or transfer of property in the United States. Meanwhile, billions of dollars of losses are caused by credit card transaction fraud every year in the United States; the key to reducing these losses is to study practical fraud detection algorithms. In the face of the characteristics of nonstationary distribution, high imbalance, and dispersion of data, Dal Pozzolo et al. [2] developed a credit fraud detection approach based on the machine learning technology to assist fraud investigators. However, there is still no public dataset on the credit card fraud that can be used to test the effectiveness of the algorithm. For online payment fraud, van Vlasselaer et al. [3] proposed an 
extended method for detecting fraudulent credit card transactions at online stores. The method mainly adopts the basic principle of RFM (recency, frequency, monetary), combines the characteristics of transaction behavior and the internal characteristics of historical customer transaction data, and verifies the algorithm through online transaction data. The results show that the algorithm considers transaction behavior characteristics and customer history and has a better prediction effect than other methods. Based on the financial transaction data, the Polish police identified the money laundering mode of a criminal suspect. Based on the case handling experience of the Polish police, Dreżewski et al. [4] developed a set of money laundering detection systems using the Apriori algorithm, the PrefixSpan algorithm, the FP growth algorithm, and the Eclat algorithm. They visualized the analysis results, which were used to detect the capital flow of criminal suspects to assist in polishing police investigations of money laundering crimes. Van Vlasselaer et al. [5] put forward a time-weighted network algorithm to identify enterprises that evade paying taxes and intentionally go bankrupt. The results show that the recognition accuracy of the algorithm is as high as $55 \%$. Aiming at fraud in electronic payments, Carcillo et al. [6] proposed an extensible real-time fraud detection system which combines big data tools (Kafka, Spark, and Cassandra) with the machine learning method. The method can solve the problems of imbalance, instability, and feedback delay. The experimental results on a large number of original credit transaction datasets show that the framework can effectively detect fraud in a large number of credit card transactions. Recently, some researchers have focused on judgment debtors. Zhang et al. [7] analyzed the possibility of law enforcement on the basis of the judgment debtor's credibility and number of transferred assets and constructed a hybrid TODIM framework to assess which the judgment debtor is more likely to repay the debt. Wu et al. [8] used a hesitant fuzzy linguistic distance method to measure whether the judgment debtor conceals property. He et al. [9] developed a novel probabilistic linguistic three-way multi-attribute decision-making method to analyze whether the judgment debtor features a concealing property behavior and ways of concealing property.

From the above analysis, a set of feasible and practical models and methods have not been formed to solve the problem of hidden property analysis of a judgment debtor. The primary purpose of hidden property analysis of a judgment debtor is to quickly and effectively assess whether the judgment debtor is likely to conceal their property. It is more efficient to extract a set of similar historical enforcement cases using the CBR technology to decide whether the judgment debtor has hidden property. The CBR technology is a useful tool to solve such problems. The main idea of the model is to analyze and assess whether the judgment debtor is likely to conceal property by extracting similar case sets from the historical enforcement case database. For complex problems with characteristics that are challenging to express and inability of establishing mathematical models, the CBR method has a perfect effect on solving such problems by imitating the human reasoning and thinking process [10-14]. So far, the research on CBR has mainly focused on the research framework and the calculation method of the similarity measure.

In the research of the CBR research framework, Wei and Dai [15] expressed the uncertainty of emission characteristics of traffic pollution sources by interval-valued intuitionistic fuzzy sets. They put forward the framework of traffic emission prediction based on the CBR method. Facing case presentation with mixed multiformat attribute values, Zheng et al. [16] transformed crisp numbers, interval numbers, and multigranularity linguistic variables into intuitionistic fuzzy numbers to present the attributes of gas explosion accidents and developed a new hybrid multi-attribute case retrieval method to extract similar historical cases. Construction risk identification mostly depends on expert knowledge or prior knowledge of the project. Somi et al. [17] introduced a new risk identification framework for renewable energy projects based on CBR. In the CBR model, fuzzy logic is used to describe the uncertainty in the process of risk identification, and similar historical renewable energy projects are extracted, which is conducive to improving the level of risk management in the construction stage. Cai et al. [18] established a case base, extracted the features of EEG, and established a CBR method for depression recognition, and the accuracy rate of 
the developed CBR approach is $91.25 \%$. Hu et al. [19] point out that CBR is widely used in engineering cost estimation, project bidding, bidding procurement, environment and sustainable management. Pla et al. [20] developed a distributed medical diagnosis decision support tool by using the CBR method, which significantly improved the efficiency of medical diagnosis under joint operation. El-fakdi et al. [21] used CBR to evaluate the case specificity in complex surgery or minimally invasive surgery and used 82 patients with aortic valve implantation in the Affiliated Hospital of Renne University as samples for demonstration. Ramos et al. [22] proposed a CBR framework based on gradient boosting feature selection and applied it to the differential diagnosis of squamous cell carcinoma and adenocarcinoma to improve the accuracy of diagnosis. The generalization ability of the method was verified by training and evaluating two independent datasets. To simulate the memory process of the human brain, Herrero [23] introduced a bottom-up CBR-learning framework and trained a group of cooperative/competitive reaction behaviors of the Aibo robot in the RoboCup environment to test the effectiveness of the proposed framework.

Similarity measure plays a significant role in CBR, which directly affects the accuracy of analysis results. In the research of similarity measure, Gilboa et al. [24-26] proposed that the similarity of cases mainly consists of average similarity and action similarity, considered the decision scheme by pairing the problem with the decision scheme, and introduced the weighted utility function to test the consistency of the preference order. Caramuta et al. [27] divided the complex decision-making problem into several nodes and obtained similarity of the decision-making problem using the graph theory method. To express the uncertainty of features in cases, Fan et al. [28,29] developed a comprehensive similarity measure to solve the problem of data diversification in the CBR method. The data types included crisp numbers, interval numbers, intuitionistic fuzzy numbers, hesitant fuzzy numbers, interval type-2 fuzzy numbers. Besides, Zhang et al. [30-34] introduced some similarity measures for the fuzzy environment. Chergui [35] studied the semantic similarity method in the community question-answering system and proposed a semantic Bayesian reasoning method for the semantic uncertainty implied in a natural language text, which had an excellent experimental effect in the community question-answering system.

Considering the advantages of the CBR method in solving complex decision-making problems, the CBR method has been extended to the legal field. Through the analysis and summary of users' transaction behavior, Adedoyin [36] proposed an improved CBR method for mobile remittance fraud detection, trying to detect abnormal patterns in transactions. The performance of this method is better than that of the single feature method. To solve the problem of employee information leakage, Boehmer [37] proposed a method of employee behavior identification based on the CBR technology, directed acyclic graphs, and the Hamming similarity measure. To crack down on illegal immigration, Chang [38] put forward a method combining CBR and expert systems to classify and analyze the patterns of illegal smuggling and restore the investigation system of cracking down on illegal smuggling. Han et al. [39] extracted the characteristics of network crime and used the CBR technology to identify hackers.

Although significant achievements have been reached in the existing research, there are still some areas to be improved.

(1) So far, there is no research on hidden property analysis of a judgment debtor. Considering the complex and changeable decision-making environment, the difficulty in feature extraction, and the difficulty in establishing a decision-making model, it is urgent to study a fast and effective method of analyzing the possibility of hidden property.

(2) In the process of case presentation, attribute values are mainly expressed by crisp numbers. With the diversification of data types, the existing case presentation in CBR cannot satisfy the needs of case presentation. It is necessary to fully consider various forms of data, such as crisp symbols, crisp numbers, interval numbers, and fuzzy linguistic variables.

(3) The similarity measure in CBR considers one data type or two and has no consideration on various types of data. 
(4) The existing CBR research has focused on case retrieval and cannot provide recommendations.

\section{CBR Approach to Hidden Property Analysis of a Judgment Debtor}

\subsection{The Framework of the CBR-Based Hidden Property Analysis of a Judgment Debtor}

In this section, we introduce the research framework of hidden property analysis of a judgment debtor based on CBR, as shown in Figure 2. The research framework consists of two parts: the research content and the relevant theoretical methods, which are placed on the left and right sides of the frame diagram, respectively. The research content includes the preparation stage and the stage of hidden property analysis. In the preparation stage, we prepare the current hidden property analysis problem and regard it as the target case. Besides, we collect some similar enforcement cases and regard them as historical cases. The stage of hiding possibility analysis mainly includes four steps: (1) case presentation structurally presents the attributes of the target case and the historical case; (2) hybrid similarity measure calculation of the similarity measure under various attributes represented by different types of data between the target case and the historical case and aggregation thereof to form the hybrid similarity measure; (3) extraction of similar historical enforcement cases, ination of the similarity threshold, and selection of a historical enforcement case set with high similarity based on the threshold value; (4) generation of a recommendation regarding the hidden property analysis problem according to the extracted similar historical enforcement cases and decision whether the judgment debtor may be concealing their property.

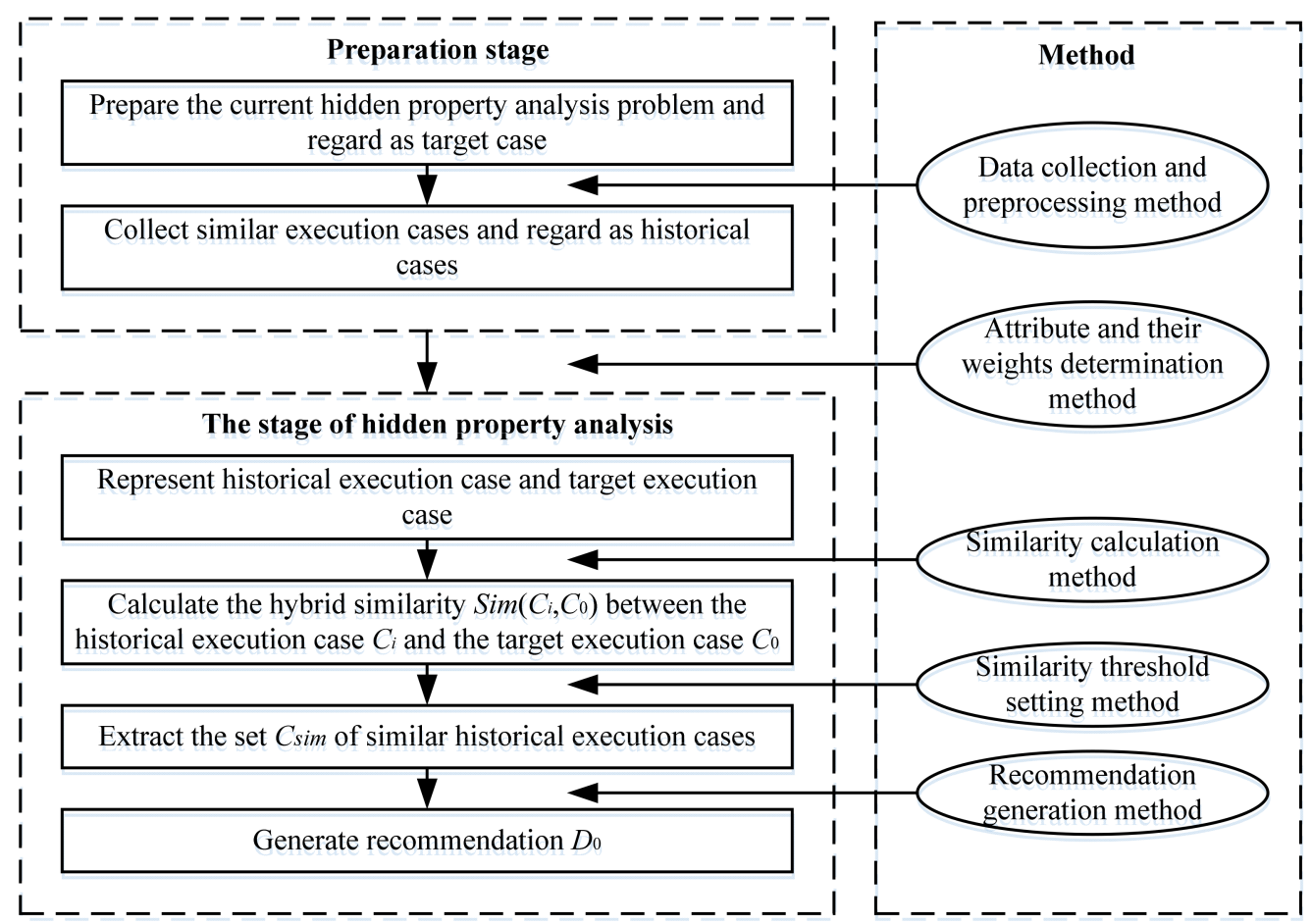

Figure 2. The framework of CBR for hidden property analysis of a judgment debtor.

\subsection{Enforcement Case Presentation}

In the process of hidden property analysis of a judgment debtor, case presentation mainly presents the historical enforcement cases and the target enforcement case according to a specific format, which provides the basis for the CBR process. Therefore, the appropriate and effective case presentation is essential for hidden property analysis. An appropriate case presentation method can improve the efficiency of extracting historical enforcement 
cases and enhance the accuracy of the results of hiding property analysis. The enforcement case presentation is as follows:

The CBR-based hidden property analysis approach includes historical enforcement cases and target cases. The case can be presented as "Case $=\{$ Enforcement case situation, hidden property analysis result\}."

Case: $C=\left\{C_{1}, C_{2}, \ldots, C_{n}\right\}$ and $C_{0}$ represent the set of historical enforcement cases and the target enforcement case, respectively, where $C_{i}$ represents the $i^{\text {th }}$ historical enforcement case, $i \in N=\{1,2, \ldots, n\}$. In the target case $C_{0}$, the result of hidden property analysis is unknown, which needs to be solved by the proposed method.

Enforcement case situation: Let $Q=\left\{Q_{1}, Q_{2}, \ldots, Q_{m}\right\}, q_{0}=\left\{q_{01}, q_{02}, \ldots, q_{0 m}\right\}$, $q_{i}=\left\{q_{i 1}, q_{i 2}, \ldots, q_{i m}\right\}$ be the collection of the attributes of enforcement cases, historical enforcement cases, and target enforcement cases, respectively, where $Q_{j}, q_{i j}, q_{0 j}$, respectively, represent the $j^{\text {th }}$ attribute of enforcement cases, historical enforcement cases, and target enforcement cases, $j \in M=\{1,2, \ldots, m\}$. Let $w^{P}=\left\{w_{1}^{P}, w_{2}^{P}, \ldots, w_{m}^{P}\right\}$ be the weight vector of the attributes of the enforcement case, where $w_{j}^{P}$ is the weight of the $j^{\text {th }}$ attribute of the enforcement case.

Meanwhile, the attribute values of target enforcement cases $q_{0 j}$ and the attribute of historical enforcement cases $q_{i j}$ can be expressed in the form of crisp symbols, crisp numbers, interval numbers, and fuzzy linguistic variables. For example, when the attribute is "gender", the value can be expressed as male or female. The value of the attribute "annual income" can be expressed as a crisp number. When describing the value of the attribute "frozen property," it is impossible to accurately estimate the exact amount of frozen property such as houses and vehicles. An interval value is more reasonable than describing the attribute by a crisp number. Meanwhile, considering there are no unified quantitative methods to express attributes such as credibility, consumption level, and work, fuzzy linguistic variables provide a suitable tool for presenting the attribute values given by the expert judges.

To distinguish between different data types, the attribute set of the enforcement case includes four subsets: crisp symbol attribute set $Q^{I}$, crisp number attribute set $Q^{I I}$, interval number attribute set $Q^{I I I}$, and fuzzy linguistic variable attribute set $Q^{I V}$, satisfying $Q=Q^{I} \cup$ $Q^{I I} \cup Q^{I I} \cup Q^{I V}$, where $Q^{I}=\left\{Q_{1}, Q_{2}, \ldots, Q_{m_{1}}\right\}, Q^{I I}=\left\{Q_{m_{1}+1}, Q_{m_{1}+2}, \ldots, Q_{m_{2}}\right\}$, $Q^{I I I}=\left\{Q_{m_{2}+1}, Q_{m_{2}+2}, \ldots, Q_{m_{3}}\right\}, Q^{I V}=\left\{Q_{m_{3}+1}, Q_{m_{3}+2}, \ldots, Q_{m}\right\}$, and the corresponding subscript sets are $M^{I}=\left\{1,2, \ldots, m_{1}\right\}, M^{I I}=\left\{m_{1}+1, m_{1}+2, \ldots, m_{2}\right\}$, $M^{I I I}=\left\{m_{2}+1, m_{2}+2, \ldots, m_{3}\right\}, M^{I V}=\left\{m_{3}+1, m_{3}+2, \ldots, m\right\}$, satisfying $M^{I} \cup M^{I I} \cup$ $M^{I I I} \cup M^{I V}=M$.

Hidden property analysis result: Let $D=\left\{D_{1}, D_{2}, \ldots, D_{h}\right\}$ be the attribute set of the results of hidden property analysis, where $D_{l}$ represents the $l^{\text {th }}$ attribute of the result, $l \in H=\{1,2, \ldots, h\}$. Let $d_{i}=\left\{d_{i 1}, d_{i 2}, \ldots, d_{i h}\right\}$ and $d_{0}=\left\{d_{0,1}, d_{0,2}, \ldots, d_{0, h}\right\}$ be the eigenvalue vectors of the judgment results of the hidden property of historical enforcement case $C_{i}$ and target enforcement case $C_{0}$, then $d_{0}=\left\{d_{0,1}, d_{0,2}, \ldots, d_{0, h}\right\}$ needs to be solved in the problem.

To sum up, the presentation of historical enforcement case $C_{i}$ and target enforcement case $C_{0}$ is shown in Table 1 , in which $X$ represents the results of hidden property analysis in target enforcement case $C_{0}$.

Table 1. Presentation of historical enforcement cases $C_{i}$ and target enforcement case $C_{0}$.

\begin{tabular}{|c|c|c|c|c|c|c|c|c|c|c|c|c|c|}
\hline & \multicolumn{9}{|c|}{ Attributes of the Enforcement Case Situation } & \multirow{2}{*}{\multicolumn{4}{|c|}{$\begin{array}{l}\text { Attributes of the Results of } \\
\text { Hidden Property Analysis }\end{array}$}} \\
\hline & \multicolumn{4}{|c|}{$Q^{I}$} & $\ldots$ & \multicolumn{4}{|c|}{$Q^{I V}$} & & & & \\
\hline & $Q_{1}$ & $Q_{2}$ & .. & $Q_{m 1}$ & ... & $Q_{m 3}$ & $Q_{m 3+1}$ & .. & $Q_{m}$ & $D_{1}$ & $D_{2}$ & $\ldots$ & $D_{h}$ \\
\hline$C_{1}$ & $q_{11}$ & $q_{12}$ & $\cdots$ & $q_{1 m 1}$ & $\cdots$ & $q_{1 m 3}$ & $q_{1 m 3+1}$ & $\cdots$ & $q_{1 m}$ & $d_{11}$ & $d_{12}$ & $\cdots$ & $d_{1 h}$ \\
\hline$C_{2}$ & $q_{21}$ & $q_{22}$ & $\ldots$ & $q_{2 m 1}$ & $\ldots$ & $q_{2 m 3}$ & $q_{2 m 3+1}$ & $\ldots$ & $q_{2 m}$ & $d_{21}$ & $d_{22}$ & .. & $d_{2 h}$ \\
\hline$\ldots$ & $\ldots$ & $\ldots$ & $\ldots$ & $\ldots$ & $\ldots$ & $\ldots$ & $\ldots$ & $\ldots$ & $\ldots$ & & & $\ldots$ & \\
\hline$C_{n}$ & $q_{n 1}$ & $q_{n 2}$ & $\ldots$ & $q_{n m 1}$ & $\ldots$ & $q_{n m 3}$ & $q_{n m 3+1}$ & $\ldots$ & $q_{n m}$ & $d_{n 1}$ & $d_{n 2}$ & $\ldots$ & $d_{n h}$ \\
\hline$C_{0}$ & $q_{01}$ & $q_{02}$ & $\ldots$ & $q_{0 m 1}$ & $\ldots$ & $q_{0 m 3}$ & $q_{0 m 3+1}$ & $\ldots$ & $q_{0 m}$ & & & & \\
\hline
\end{tabular}




\subsection{Hybrid Similarity Measure between Historical Enforcement Cases and the Target Enforcement Case}

In enforcement cases, the attribute values mainly include four data types: crisp symbols, crisp numbers, interval numbers, and fuzzy linguistic variables. The similarity measures of different data types are also different. Here, we introduce the similarity measures of attribute values of the four different data types.

\section{(1) Crisp symbols}

When the attribute value is a crisp symbol, that is, $Q_{j} \in Q^{I}$, all the possible values of the attribute can be provided by a simple enumeration method. For example, when the attribute is "gender," the value can be expressed as male or female. Let $q_{i j}^{I}$, $q_{0 j}^{I}$ be the attribute values of historical enforcement case $C_{i}$ and target enforcement case $C_{0}$, respectively, represented by crisp symbols; then, similarity measure $\operatorname{sim}\left(C_{0}, C_{i}\right)$ under attributes $Q^{I}$ between historical enforcement case $C_{i}$ and target enforcement case $C_{0}$ is defined as follows:

$$
\operatorname{sim}\left(C_{0}, C_{i}\right)=\left\{\begin{array}{c}
1, q_{i j}^{I}=q_{0 j}^{I} \\
0, q_{i j}^{I} \neq q_{0 j}^{I}
\end{array} \quad i \in N, j \in M^{I}\right.
$$

\section{(2) Crisp numbers}

When the attribute value is a crisp number, that is, $Q_{j} \in Q^{I I}$, if $q_{i j}^{I I}, q_{0 j}^{I I}$ are, respectively, the attribute values of historical enforcement case $C_{i}$ and target enforcement case $C_{0}$ represented by the crisp number, the calculation formula of the different degree under attribute $Q^{I I}$ between historical enforcement case $C_{i}$ and target enforcement case $C_{0}$ is as follows.

$$
\delta\left(q_{i j}^{I I}, q_{0 j}^{I I}\right)=\frac{1}{\Delta_{j}^{I I m a x}} \sqrt{\left(q_{i j}^{I I}-q_{0 j}^{I I}\right)^{2}}, i \in N, j \in M^{I I}
$$

where $\Delta_{j}^{I I \max }=\max \left\{\sqrt{\left(q_{i j}^{I I}-q_{0 j}^{I I}\right)^{2}} \mid i \in N\right\}, \delta\left(q_{i j}^{I I}, q_{0 j}^{I I}\right) \in[0,1]$.

Under attribute $Q^{I I}$, similarity measure $\operatorname{sim}\left(C_{0}, C_{i}\right)$ between historical enforcement case $C_{i}$ and target enforcement case $C_{0}$ is based on the distance measure considering the reflexivity, symmetry, and other properties of the similarity and constructed using the negative exponential function [40-42]. Therefore, the calculation formula is as follows:

$$
\operatorname{sim}\left(C_{0}, C_{i}\right)=\exp \left[-\delta\left(q_{i j}^{I I}, q_{0 j}^{I I}\right)\right], i \in N, j \in M^{I I}
$$

\section{(3) Interval numbers}

When the attribute value is an interval number, that is, $Q_{j} \in Q^{I I I}$, the interval number has certain advantages in describing the uncertainty of the attribute value. For example, when representing the attribute value of "frozen property," the specific amount of frozen property, such as houses and vehicles, cannot be accurately estimated according to the market circulation value. Generally, the attribute value is expressed with an interval number, which is more reasonable than the crisp number. Suppose $q_{i j}^{I I I}$ and $q_{0 j}^{I I I}$ are the attribute values of historical enforcement case $C_{i}$ and target enforcement case $C_{0}$ expressed by interval numbers, where $q_{i j}^{I I I}=\left[q_{i j}, \bar{q}_{i j}\right], q_{0 j}^{I I I}=\left[q_{0 j}, \bar{q}_{0 j}\right]$; then, the calculation formula of the different degree between historical enforcement case $C_{i}$ and target enforcement case $C_{0}$ is as follows:

$$
\delta\left(q_{i j}^{I I I}, q_{0 j}^{I I I}\right)=\frac{1}{\Delta_{j}^{I I I m a x}} \sqrt{\left(q_{i j}^{I I I}-q_{0 j}^{I I I}\right)^{2}+\left(\bar{q}_{i j}^{I I I}-\bar{q}_{0 j}^{I I I}\right)^{2}}, i \in N, j \in M^{I I I}
$$


where $\Delta_{j}^{I I I \max }=\max \left\{\sqrt{\left(q_{i j}^{I I I}-q_{0 j}^{I I I}\right)^{2}+\left(\bar{q}_{i j}^{I I I}-\bar{q}_{0 j}^{I I I}\right)^{2}} \mid i \in N\right\}, \delta\left(q_{i j}^{I I I}, q_{0 j}^{I I I}\right) \in[0,1]$.

Under attribute $Q^{I I I}$, similarity measure $\operatorname{sim}\left(C_{0}, C_{i}\right)$ is as follows:

$$
\operatorname{sim}\left(C_{0}, C_{i}\right)=\exp \left[-\delta\left(q_{i j}^{I I I}, q_{0 j}^{I I I}\right)\right], i \in N, j \in M^{I I I}
$$

(4) Fuzzy linguistic variables

When the attribute values are fuzzy linguistic variables, that is, $Q_{j} \in Q^{I V}$, fuzzy linguistic variables have certain advantages in the expression of uncertainty and fuzziness of the attribute values. For example, there is no unified quantitative standard for the attribute "credibility," and fuzzy linguistic variables such as "poor," "medium," and "good" are usually used. Suppose that $q_{i j}^{I V}$ and $q_{0 j}^{I V}$ are the attribute values of historical enforcement case $C_{i}$ and target enforcement case $C_{0}$ represented by fuzzy triangular numbers, respectively, where $\widetilde{q}_{i j}^{I V}=\left(d_{i j}^{a}, d_{i j}^{b}, d_{i j}^{c}\right), \widetilde{q}_{0 j}^{I V}=\left(d_{0 j}^{a}, d_{0 j}^{b}, d_{0 j}^{c}\right)$. Different degree $\delta\left(q_{i j}^{I V}, q_{0 j}^{I V}\right)$ between historical enforcement case $C_{i}$ and target enforcement case $C_{0}$ is as follows:

$$
\delta\left(q_{i j}^{I V}, q_{0 j}^{I V}\right)=\frac{1}{\widetilde{\Delta}_{j}^{\max }} \sqrt{\left(q_{i j}^{a}-q_{0 j}^{a}\right)^{2}+\left(q_{i j}^{b}-q_{0 j}^{b}\right)^{2}+\left(q_{i j}^{c}-q_{0 j}^{c}\right)^{2}}, i \in N, j \in M^{I V}
$$

where $\widetilde{\Delta}_{j}^{\max }=\max \left\{\sqrt{\left(q_{i j}^{a}-q_{0 j}^{a}\right)^{2}+\left(q_{i j}^{b}-q_{0 j}^{b}\right)^{2}+\left(q_{i j}^{c}-q_{0 j}^{c}\right)^{2}} \mid i \in N\right\}, \delta\left(q_{i j}^{I V}, q_{0 j}^{I V}\right) \in$ $[0,1]$.

Under attribute $Q^{I V}$, similarity measure $\operatorname{sim}\left(C_{0}, C_{i}\right)$ is

$$
\operatorname{sim}\left(C_{0}, C_{i}\right)=\exp \left[-\delta\left(q_{i j}^{I V}, q_{0 j}^{I V}\right)\right], i \in N, j \in M^{I V}
$$

(5) Calculate the hybrid similarity measure between historical enforcement cases and the target enforcement case

Using Equations (1)-(7), similarity measure $\operatorname{sim}_{j}\left(C_{0}, C_{i}\right)$ of attribute $Q_{j}$ between historical enforcement case $C_{i}$ and target enforcement case $C_{0}$ can be obtained, and the hybrid similarity measure can be obtained by aggregating similarity measure $\operatorname{sim}_{j}\left(C_{0}, C_{i}\right)$ of attribute $Q_{j}$.

Suppose that $\operatorname{Sim}\left(C_{0}, C_{i}\right)$ is the hybrid similarity measure between historical enforcement case $C_{i}$ and target enforcement case $C_{0}$; then, the calculation formula of the hybrid similarity measure is as follows:

$$
\operatorname{sim}\left(C_{0}, C_{i}\right)=\frac{\sum_{j=1}^{M} \operatorname{sim}_{j}\left(C_{0}, C_{i}\right) w_{j}}{\sum_{j=1}^{M} w_{j}}
$$

Obviously, $\operatorname{Sim}\left(C_{0}, C_{i}\right) \in[0,1]$ and the larger $\operatorname{Sim}\left(C_{0}, C_{i}\right)$, the higher the similarity between historical case $C_{i}$ and target case $C_{0}$.

\subsection{Extraction of Similar Historical Enforcement Cases}

Usually, similar historical enforcement cases are extracted by the hybrid similarity measure. The higher the hybrid similarity measure between a historical case and the target case, the more referential it is to the target case. Therefore, it is necessary to extract historical enforcement cases and construct a set of similar historical cases. To obtain a more reasonable similar historical case set, we need to set the hybrid similarity threshold. 
Let $\tau$ be the similarity threshold, then the calculation formula of similarity threshold $\tau$, according to the principle in [28], is defined as follows:

$$
\tau=\operatorname{Sim}^{(+)}-\frac{\operatorname{Sim}^{(+)}-\operatorname{Sim}^{(-)}}{3}
$$

where $\operatorname{Sim}^{(+)}=\max \left\{\operatorname{Sim}\left(C_{0}, C_{i}\right) \mid i \in N\right\}, \operatorname{Sim}(-)=\min \left\{\operatorname{Sim}\left(C_{0}, C_{i}\right) \mid i \in N\right\}$.

When $\operatorname{Sim}\left(C_{0}, C_{i}\right)>\tau$, it means that the historical enforcement case has a high similarity with the target enforcement case and can be used for reference, so historical enforcement cases with high similarity are extracted. According to this principle (Equation (9)), all the historical enforcement cases greater than similarity threshold $\tau$ are extracted, and set $C^{\operatorname{Sim}}$ of similar historical enforcement cases is constructed as follows:

$$
C^{\text {Sim }}=\left\{C_{i} \mid i \in N^{\text {Sim }}\right\}
$$

where $N^{\operatorname{Sim}}=\left\{i \mid \operatorname{Sim}\left(C_{0}, C_{i}\right)>\tau, i \in N\right\}, N^{\operatorname{Sim}}$ being the subscript set of similar historical enforcement cases with vital reference significance. Obviously, $C^{\operatorname{Sim}} \subset C, N^{\operatorname{Sim}} \subset N$.

\subsection{Generation of Recommendations for Hidden Property Analysis}

As a result of hidden property analysis, the attribute value can be composed of crisp symbols, crisp numbers, interval numbers, or fuzzy linguistic variables. When the attribute value is a crisp symbol, the most frequent opinion is considered the recommendation opinion. For example, among the five similar enforcement cases extracted, in four of the extracted cases, the judgment debtors concealed property. In one of the extracted cases the judgment debtor had no hidden property. Therefore, we can judge that the judgment debtor in the target case also concealed their property. When the attribute value is a crisp number, an interval number, or a fuzzy linguistic variable, the attribute of the recommendation of hidden property analysis is aggregated with the attribute values from similar enforcement cases, and the weight of each similar historical case is converted using the hybrid similarity measure. The calculation method of the attribute value as a result of hidden property analysis in the target enforcement case is as follows:

(1) If attribute value $d_{0 l}$ of the result of hidden property analysis is a crisp symbol, attribute value $d_{0 l}$ is defined as follows

$$
d_{0 l}=\left\{d_{k l} \mid k=\left\{i \mid \max _{i}\left(\operatorname{Sim}\left(C_{i}, C_{0}\right)\right), i \in N^{\operatorname{Sim}}\right\}\right\}
$$

(2) If attribute value $d_{0 l}$ of the results of the analysis of the possibility of hidden property is a crisp number, an interval number, or a fuzzy linguistic variable, attribute value $d_{0 l}$ is defined as follows:

$$
d_{0 l}=\frac{\sum_{1}^{i=N^{S i m}} d_{i l} \operatorname{Sim}\left(C_{i}, C_{0}\right)}{\sum_{i}^{N^{S i m}} \operatorname{Sim}\left(C_{i}, C_{0}\right)}
$$

To sum up, the steps of the CBR approach for hidden property analysis of a judgment debtor are as follows:

Step 1: calculate similarity measure $\operatorname{sim}\left(C_{i}, C_{0}\right)$ of attribute $Q_{j}$ between historical enforcement cases $C_{i}$ and target enforcement case $C_{0}$ using Equations (1)-(7).

Step 2: give the weight vector $W$ of the attributes of the enforcement case situation.

Step 3: calculate hybrid similarity measure $\operatorname{Sim}\left(C_{i}, C_{0}\right)$ between historical enforcement cases $C_{i}$ and target enforcement case $C_{0}$, using Equation (8).

Step 4: ensure similarity threshold $\tau$ with Equation (9). 
Step 5: extract historical cases with vital reference significance according to the extraction rules of similar enforcement cases (Equation (10)) and construct set $C^{\text {Sim }}$ of similar historical enforcement cases.

Step 6: using Equation (11) or (12), calculate attribute value $d_{0 l}$ of the results of hidden property analysis and give optimal recommendation.

\section{Case Study}

\subsection{The Process of Hidden Property Analysis}

The CBR-based approach is a useful tool to extract similar historical cases and use the information and knowledge of similar historical cases to generate the recommendation of the target enforcement case effectively. To improve the efficiency of handling enforcement cases, we took the decision-making of enforcement cases as an example to demonstrate effectiveness of the proposed method.

Considering that a judgment debtor is the subject of the enforcement case, we selected some features of the judgment debtor as the attributes of the enforcement case, including gender $\left(Q_{1}\right)$, age $\left(Q_{2}\right)$, annual income $\left(Q_{3}, 10,000\right.$ yuan/year), frozen property/enforcement target amount $\left(Q_{4}\right)$, educational background $\left(Q_{5}\right)$, comprehensive family strength $\left(Q_{6}\right)$, work nature $\left(Q_{7}\right)$, transaction behavior $\left(Q_{8}\right)$, consumption level $\left(Q_{9}\right)$, and credibility $\left(Q_{10}\right)$. The data types of each attribute are shown in Table 2 . For fuzzy linguistic variables, the linguistic term set used is shown in Table $3 . W=(0.1,0.1,0.1,0.1,0.1,0.1,0.1,0.1,0.1,0.1)^{T}$ is the weight of the attributes of enforcement cases given by the experts. We collected 15 historical cases $\left(C_{1}, C_{2}, \ldots, C_{15}\right)$ shown in Table 4 .

Table 2. The meanings of the attributes and their corresponding data types.

\begin{tabular}{ccc}
\hline Attributes & Meanings of Attributes & Data Type of the Attributes \\
\hline$Q_{1}$ & Gender & Crisp symbol \\
$Q_{2}$ & Age & Crisp number \\
$Q_{3}$ & Annual income & Crisp number \\
$Q_{4}$ & Frozen property/enforcement target & Interval number \\
$Q_{5}$ & Educational background & Fuzzy linguistic variable \\
$Q_{6}$ & Comprehensive family strength & Fuzzy linguistic variable \\
$Q_{7}$ & Work & Fuzzy linguistic variable \\
$Q_{8}$ & Trading behavior & Fuzzy linguistic variable \\
$Q_{9}$ & Consumption level & Fuzzy linguistic variable \\
$Q_{10}$ & Credibility & Fuzzy linguistic variable \\
\hline
\end{tabular}

Table 3. Linguistic terms of fuzzy linguistic variables and their corresponding triangular fuzzy numbers.

\begin{tabular}{|c|c|c|c|c|c|c|c|}
\hline $\begin{array}{l}\text { Linguistic } \\
\text { Terms }\end{array}$ & $\begin{array}{l}\text { Educational } \\
\text { Background }\end{array}$ & $\begin{array}{c}\text { Comprehensive } \\
\text { Family } \\
\text { Strength }\end{array}$ & Work & $\begin{array}{l}\text { Trading } \\
\text { Behavior }\end{array}$ & $\begin{array}{c}\text { Consumption } \\
\text { Level }\end{array}$ & Credibility & $\begin{array}{l}\text { Corresponding } \\
\text { Triangular } \\
\text { Fuzzy Number }\end{array}$ \\
\hline$s_{0}$ & - & $\begin{array}{l}\text { Extremely } \\
\text { bad }\end{array}$ & $\begin{array}{l}\text { Extremely } \\
\text { unstable }\end{array}$ & $\begin{array}{l}\text { Extremely } \\
\quad \text { risk } \\
\text { preference }\end{array}$ & $\begin{array}{l}\text { Extremely } \\
\text { high }\end{array}$ & $\begin{array}{l}\text { Extremely } \\
\text { bad }\end{array}$ & $(0,0,0.17)$ \\
\hline$s_{1}$ & $\begin{array}{c}\text { Middle school } \\
\text { degree }\end{array}$ & Very bad & Very unstable & $\begin{array}{c}\text { Very high risk } \\
\text { preference }\end{array}$ & Very high & Very bad & $(0,0.17,0.33)$ \\
\hline$s_{2}$ & $\begin{array}{c}\text { High school } \\
\text { degree }\end{array}$ & Bad & Unstable & $\begin{array}{c}\text { Risk } \\
\text { preference }\end{array}$ & High & Bad & $(0.17,0.33,0.5)$ \\
\hline$s_{3}$ & $\begin{array}{c}\text { Senior college } \\
\text { degree }\end{array}$ & Medium & Medium & Medium & Medium & Medium & $(0.33,0.5,0.67)$ \\
\hline$s_{4}$ & $\begin{array}{c}\text { Bachelor's } \\
\text { degree }\end{array}$ & Good & Stable & Risk-averse & Low & Good & $(0.5,0.67,0.83)$ \\
\hline$s_{5}$ & $\begin{array}{l}\text { Master's } \\
\text { degree }\end{array}$ & Very good & Very stable & $\begin{array}{c}\text { Very } \\
\text { risk-averse }\end{array}$ & Very low & Very good & $(0.67,0.83,1)$ \\
\hline$s_{6}$ & $\begin{array}{l}\text { Doctor's } \\
\text { degree }\end{array}$ & $\begin{array}{l}\text { Extremely } \\
\text { good }\end{array}$ & $\begin{array}{l}\text { Extremely } \\
\text { stable }\end{array}$ & $\begin{array}{l}\text { Extremely } \\
\text { risk-averse }\end{array}$ & $\begin{array}{c}\text { Extremely } \\
\text { low }\end{array}$ & $\begin{array}{l}\text { Extremely } \\
\text { good }\end{array}$ & $(0.83,1,1)$ \\
\hline
\end{tabular}


Table 4. Attribute value $Q_{j}$ of historical enforcement cases $C_{i}$ and target enforcement case $C_{0}$.

\begin{tabular}{|c|c|c|c|c|c|c|c|c|c|c|c|}
\hline & $Q_{1}$ & $Q_{2}$ & $Q_{3}$ & $Q_{4}$ & $Q_{5}$ & $Q_{6}$ & $Q_{7}$ & $Q_{8}$ & $Q_{9}$ & $Q_{10}$ & Recommendation \\
\hline$C_{1}$ & $\mathrm{M}$ & 52 & 15.6 & {$[0.00,0.00]$} & $s_{4}$ & $s_{3}$ & $s_{2}$ & $s_{2}$ & $s_{2}$ & $s_{3}$ & $D_{1}$ \\
\hline$C_{2}$ & $\mathrm{M}$ & 28 & 10.3 & {$[0.05,0.15]$} & $s_{2}$ & $s_{3}$ & $s_{2}$ & $s_{3}$ & $s_{2}$ & $s_{2}$ & $D_{1}$ \\
\hline$C_{3}$ & $\mathrm{M}$ & 32 & 12.1 & {$[0.10,0.14]$} & $s_{4}$ & $s_{4}$ & $s_{3}$ & $s_{2}$ & $s_{3}$ & $s_{3}$ & $D_{1}$ \\
\hline $\mathrm{C}_{4}$ & $\mathrm{M}$ & 46 & 17.5 & {$[0.00,0.12]$} & $s_{5}$ & $s_{4}$ & $s_{4}$ & $s_{4}$ & $s_{4}$ & $s_{4}$ & $D_{3}$ \\
\hline$C_{5}$ & $\mathrm{M}$ & 57 & 7.6 & {$[1.30,1.40]$} & $s_{3}$ & $s_{5}$ & $s_{2}$ & $s_{1}$ & $s_{1}$ & $s_{2}$ & $D_{3}$ \\
\hline $\mathrm{C}_{6}$ & $\mathrm{M}$ & 39 & 12.3 & {$[0.00,0.06]$} & $s_{4}$ & $s_{4}$ & $s_{3}$ & $s_{3}$ & $s_{3}$ & $s_{2}$ & $D_{1}$ \\
\hline$C_{7}$ & $\mathrm{M}$ & 32 & 13.5 & {$[0.05,0.11]$} & $s_{4}$ & $s_{3}$ & $s_{4}$ & $s_{3}$ & $s_{3}$ & $s_{3}$ & $D_{1}$ \\
\hline$C_{8}$ & M & 36 & 10.6 & {$[0.01,0.01]$} & $s_{3}$ & $s_{2}$ & $s_{3}$ & $s_{2}$ & $s_{2}$ & $s_{2}$ & $D_{2}$ \\
\hline$C_{9}$ & $\mathrm{M}$ & 41 & 5.0 & {$[0.02,0.02]$} & $s_{2}$ & $s_{3}$ & $s_{1}$ & $s_{2}$ & $s_{1}$ & $s_{2}$ & $D_{2}$ \\
\hline$C_{10}$ & $\mathrm{M}$ & 44 & 13.0 & {$[0.00,0.08]$} & $s_{3}$ & $s_{2}$ & $s_{3}$ & $s_{2}$ & $s_{2}$ & $s_{2}$ & $D_{1}$ \\
\hline$C_{11}$ & $\mathrm{M}$ & 43 & 4.7 & {$[0.01,0.01]$} & $s_{1}$ & $s_{2}$ & $s_{1}$ & $s_{1}$ & $s_{0}$ & $s_{1}$ & $D_{2}$ \\
\hline$C_{12}$ & $\mathrm{M}$ & 48 & 16.1 & {$[0.10,0.20]$} & $S_{5}$ & $s_{2}$ & $S_{5}$ & $s_{4}$ & $s_{4}$ & $s_{4}$ & $D_{1}$ \\
\hline$C_{13}$ & $\mathrm{~F}$ & 33 & 8.7 & {$[0.05,0.09]$} & $s_{3}$ & $s_{3}$ & $s_{2}$ & $s_{2}$ & $s_{2}$ & $s_{2}$ & $D_{1}$ \\
\hline$C_{14}$ & $\mathrm{~F}$ & 35 & 12.5 & {$[1.20,1.28]$} & $s_{3}$ & $s_{5}$ & $s_{3}$ & $s_{4}$ & $s_{3}$ & $s_{3}$ & $D_{3}$ \\
\hline$C_{15}$ & $\mathrm{~F}$ & 42 & 10.5 & {$[0.20,0.24]$} & $s_{4}$ & $s_{4}$ & $s_{4}$ & $s_{3}$ & $s_{4}$ & $s_{3}$ & $D_{1}$ \\
\hline$C_{0}$ & $\mathrm{M}$ & 41 & 12.0 & {$[0.05,0.15]$} & $s_{3}$ & $s_{3}$ & $s_{2}$ & $s_{3}$ & $s_{3}$ & $s_{2}$ & - \\
\hline
\end{tabular}

Remark: " $\mathrm{M}$ " represents male and " $\mathrm{F}$ " represents female.

For target enforcement case $C_{0}$, the judgment debtor was 41 years old, male; the detailed information of the judgment debtor is shown in Tabel 4. We assessed whether the judgment debtor concealed property or not by calculating the hybrid similarity measure between the target enforcement case and historical enforcement cases. The recommendation of hidden property analysis mainly includes the judgment debtor's refusal to perform the legal instrument by hiding property $\left(D_{1}\right)$, the judgment debtor's lack of ability to perform the legal instrument $\left(D_{2}\right)$, and the judgment debtor's performance of the legal instrument $\left(D_{3}\right)$. The information on the attributes of historical enforcement cases and the target enforcement case are shown in Table 4.

According to the above information, hidden property analysis of the judgment debtor in the target enforcement case was carried out, and the steps were as follows:

Step 1: using Equations (1)-(7), calculate similarity measure $\operatorname{sim}\left(C_{i}, C_{0}\right)$ under each attribute $Q_{j}$ between historical enforcement cases $C_{i}$ and target enforcement case $C_{0}$, as shown in Table 5.

Table 5. Similarity measures of attribute $Q_{j}$ between historical enforcement cases $C_{i}$ and target enforcement case $C_{0}$.

\begin{tabular}{ccccccccccc}
\hline $\operatorname{sim}\left(C_{i}, C_{0}\right)$ & $Q_{1}$ & $Q_{2}$ & $Q_{3}$ & $Q_{4}$ & $Q_{5}$ & $Q_{6}$ & $Q_{7}$ & $Q_{8}$ & $Q_{9}$ & $Q_{10}$ \\
\hline$C_{1}$ & 1.00 & 0.50 & 0.61 & 1.00 & 0.61 & 0.92 & 1.00 & 0.61 & 0.72 & 0.61 \\
$C_{2}$ & 1.00 & 0.44 & 0.61 & 1.00 & 0.79 & 1.00 & 1.00 & 1.00 & 0.72 & 1.00 \\
$C_{3}$ & 1.00 & 0.57 & 0.61 & 0.61 & 0.99 & 0.98 & 0.72 & 0.61 & 1.00 & 0.61 \\
$C_{4}$ & 1.00 & 0.73 & 0.37 & 0.61 & 0.47 & 0.97 & 0.51 & 0.61 & 0.72 & 0.37 \\
$C_{5}$ & 1.00 & 0.37 & 1.00 & 0.37 & 0.55 & 0.37 & 1.00 & 0.37 & 0.51 & 1.00 \\
$C_{6}$ & 1.00 & 0.88 & 0.61 & 0.61 & 0.96 & 0.95 & 0.72 & 1.00 & 1.00 & 1.00 \\
$C_{7}$ & 1.00 & 0.57 & 0.61 & 1.00 & 0.81 & 0.98 & 0.51 & 1.00 & 1.00 & 0.61 \\
$C_{8}$ & 1.00 & 0.73 & 1.00 & 0.61 & 0.83 & 0.93 & 0.72 & 0.61 & 0.72 & 1.00 \\
$C_{9}$ & 1.00 & 1.00 & 0.61 & 1.00 & 0.38 & 0.94 & 0.72 & 0.61 & 0.51 & 1.00 \\
$C_{10}$ & 1.00 & 0.83 & 1.00 & 0.61 & 0.87 & 0.95 & 0.72 & 0.61 & 0.72 & 1.00 \\
$C_{11}$ & 1.00 & 0.88 & 0.37 & 0.61 & 0.37 & 0.93 & 0.72 & 0.37 & 0.37 & 0.61 \\
$C_{12}$ & 1.00 & 0.65 & 0.37 & 0.61 & 0.57 & 0.96 & 0.37 & 0.61 & 0.72 & 0.37 \\
$C_{13}$ & 0.37 & 0.61 & 1.00 & 1.00 & 0.64 & 0.98 & 1.00 & 0.61 & 0.72 & 1.00 \\
$C_{14}$ & 0.37 & 0.69 & 1.00 & 0.37 & 0.93 & 0.40 & 0.72 & 0.61 & 1.00 & 0.61 \\
$C_{15}$ & 0.37 & 0.94 & 0.61 & 0.61 & 0.81 & 0.91 & 0.51 & 1.00 & 0.72 & 0.61 \\
\hline
\end{tabular}

Step 2: calculate hybrid similarity measure $\operatorname{Sim}\left(C_{i}, C_{0}\right)$ between historical enforcement cases $C_{i}$ and target enforcement case $C_{0}$ using Equation (8) as shown in Table 6. 
The results show that historical case $C_{6}$ was the most similar to target enforcement case $C_{0}, \operatorname{Sim}\left(C_{6}, C_{0}\right)=0.87$. The second and third similar cases were $C_{2}$ and $C_{10}$, $\operatorname{Sim}\left(C_{2}, C_{0}\right)=0.86, \operatorname{Sim}\left(C_{10}, C_{0}\right)=0.83$, and the most dissimilar cases were $C_{11}$ and $C_{12}$, $\operatorname{Sim}\left(C_{11}, C_{0}\right)=\operatorname{Sim}\left(C_{12}, C_{0}\right)=0.62$.

Table 6. Hybrid similarity measure $\operatorname{Sim}\left(C_{i}, C_{0}\right)$ between historical enforcement cases $C_{i}$ and target enforcement case $C_{0}$.

\begin{tabular}{ccccccccc}
\hline \multirow{2}{*}{ Similarity Measure } & \multicolumn{8}{c}{ Historical Cases } \\
\cline { 2 - 10 } & $C_{1}$ & $C_{2}$ & $C_{3}$ & $C_{4}$ & $C_{5}$ & $C_{6}$ & $C_{7}$ & $C_{8}$ \\
\hline $\operatorname{Sim}\left(C_{i}, C_{0}\right)$ & 0.76 & 0.86 & 0.77 & 0.63 & 0.65 & 0.87 & 0.81 & 0.81 \\
\hline \multirow{2}{*}{$\operatorname{Similarity~Measure~}$} & $C_{\mathbf{9}}$ & $C_{\mathbf{1 0}}$ & $C_{11}$ & $C_{12}$ & $C_{13}$ & $C_{14}$ & $C_{15}$ \\
\hline $\operatorname{Sim}\left(C_{i}, C_{0}\right)$ & 0.78 & 0.83 & 0.62 & 0.62 & 0.79 & 0.67 & 0.71 \\
\hline
\end{tabular}

Step 3: similarity threshold $\tau$ calculated using Equation (9) was 0.79. That is, if similarity measure $\operatorname{Sim}\left(C_{i}, C_{0}\right)$ between historical cases $C_{i}$ and target case $C_{0}$ is more significant than 0.79 , it can be added to the set of similar historical cases.

$$
\tau=\operatorname{Sim}^{(+)}-\frac{\operatorname{Sim}^{(+)}-\operatorname{Sim}^{(-)}}{3}=0.87-\frac{0.87-0.62}{3}=0.79 .
$$

Step 4: similarity threshold $\tau$ was 0.79 . Using Equation (10), historical cases with vital reference significance were extracted, and a similar historical enforcement case set was constructed as $C^{\mathrm{Sim}}=\left\{C_{2}, C_{6}, C_{7}, C_{8}, C_{10}\right\}$.

Step 5: using Equation (11) or (12), calculate the attribute value of the recommendation and give recommendations.

The recommendation of hidden property analysis includes three kinds: the judgment debtor refuses to perform the legal instrument by hiding property $\left(D_{1}\right)$, the judgment debtor has no ability to perform the legal instrument $\left(D_{2}\right)$, or the judgment debtor performs the legal instrument $\left(D_{3}\right)$, which can be regarded as crisp symbols. According to set $C^{S i m}$ of similar historical cases, there were only two recommendations: $D_{1}$ and $D_{2}$, as shown in Table 7.

Table 7. Similar historical cases.

\begin{tabular}{ccc}
\hline Similar Historical Case & Similarity & Recommendation \\
\hline$C_{2}$ & 0.86 & $D_{1}$ \\
$C_{6}$ & 0.87 & $D_{1}$ \\
$C_{7}$ & 0.81 & $D_{1}$ \\
$C_{8}$ & 0.81 & $D_{2}$ \\
$C_{10}$ & 0.83 & $D_{1}$ \\
\hline
\end{tabular}

Therefore, the probabilities of these two kinds of recommendations were calculated using Equation (10):

$$
\begin{aligned}
& p\left(D_{1}\right)=\frac{\sum_{i \in D_{1} \operatorname{sim}} \operatorname{Sim}\left(C_{i}, C_{0}\right)}{\sum_{i \in N^{\operatorname{Sim}}} \operatorname{Sim}\left(C_{i}, C_{0}\right)}=\frac{0.86+0.87+0.81+0.83}{0.86+0.87+0.81+0.81+0.83}=0.81 \\
& p\left(D_{2}\right)=\frac{\sum_{i \in D_{2} \operatorname{sim}} \operatorname{Sim}\left(C_{i}, C_{0}\right)}{\sum_{i \in N^{\text {Sim }}} \operatorname{Sim}\left(C_{i}, C_{0}\right)}=\frac{0.81}{0.86+0.87+0.81+0.81+0.83}=0.19
\end{aligned}
$$


The above analysis shows that the recommendation was that the judgment debtor in the target enforcement case refused to perform the legal instrument by hiding property. According to the detailed information in Table 4, the judgment debtor in the target enforcement case was 41 years old and had unstable work, low credibility. Five similar historical enforcement cases $\left\{C_{2}, C_{6}, C_{7}, C_{8}, C_{10}\right\}$ were extracted using the hybrid similarity measure. Four of those judgment debtors featured a hidden property behavior, and one of them was unable to perform the legal instrument. Therefore, the judgment debtor in the target enforcement case was likely to hide property and needed to be tracked. Actually, the recommendation of CBR-based hidden property analysis was consistent with the practical judicial implementation. The result showed that the developed CBR method can provide a clear and effective way to quickly assess the possibility of property being hidden, reduce the work pressure on law enforcement officers, and improve the efficiency of handling enforcement cases.

\subsection{Comparative Analysis}

To illustrate effectiveness and novelty of the developed CBR method for hidden property analysis of a judgment debtor, we compared the developed CBR method with the distance-based method for hidden property analysis [8]. The main idea of Wu's method [8] is to judge whether the judgment debtor hides property by calculating the distance between the judgment debtor in the target case and in historical cases. Here, hybrid distance measure $\operatorname{Dis}\left(C_{i}, C_{0}\right)$ between historical enforcement case $C_{i}$ and target enforcement case $C_{0}$ was defined as follows:

$$
\operatorname{Dis}\left(C_{0}, C_{i}\right)=\frac{\sum_{j=1}^{M} \operatorname{dis}_{j}\left(C_{0}, C_{i}\right) w_{j}}{\sum_{j=1}^{M} w_{j}}
$$

Then, the hybrid distance result was shown in Table 8. The judgment debtor in target case $C_{0}$ was closest to the judgment debtor in historical case $C_{6}$. Namely, Dis $\left(C_{6}, C_{0}\right)=0.13$. The recommendation was $D_{1}$-the judgment debtor in $C_{0}$ hides property.

Table 8. Hybrid distance measure $\operatorname{Dis}\left(C_{i}, C_{0}\right)$ between historical enforcement cases $C_{i}$ and target enforcement case $C_{0}$.

\begin{tabular}{ccccccccc}
\hline \multirow{2}{*}{ Distance Measure } & \multicolumn{8}{c}{ Historical Cases } \\
\cline { 2 - 10 } & $C_{\mathbf{1}}$ & $C_{\mathbf{2}}$ & $C_{\mathbf{3}}$ & $C_{\mathbf{4}}$ & $C_{\mathbf{5}}$ & $C_{\mathbf{6}}$ & $C_{\mathbf{7}}$ & $C_{\mathbf{8}}$ \\
\hline$d\left(C_{i}, C_{0}\right)$ & 0.24 & 0.14 & 0.23 & 0.37 & 0.35 & 0.13 & 0.19 & 0.19 \\
\hline \multirow{2}{*}{ Distance Measure } & \multicolumn{7}{c}{ Historical Cases } \\
\cline { 2 - 10 } & $C_{\mathbf{9}}$ & $C_{\mathbf{1 0}}$ & $C_{\mathbf{1 1}}$ & $C_{\mathbf{1 2}}$ & $C_{\mathbf{1 3}}$ & $C_{\mathbf{1 4}}$ & $C_{\mathbf{1 5}}$ \\
\hline$d\left(C_{i}, C_{0}\right)$ & 0.22 & 0.17 & 0.38 & 0.38 & 0.21 & 0.33 & 0.29 \\
\hline
\end{tabular}

Although the recommendation obtained by Wu's method [8] was the same as that obtained with the developed CBR method, the developed CBR method was more reasonable than Wu's method. Wu's method suggests extracting only one judgment debtor with the closest distance, while five historical enforcement cases are extracted when using the developed CBR method. The assessment refers to just one judgment debtor's recommendation, which will greatly increase the hidden property analysis error rate. Expert judges will assess whether the judgment debtor hides property according to the similar cases' recommendations, which will improve reliability of the analysis result. Therefore, the analysis result obtained using the developed CBR method was more reasonable than that obtained with $\mathrm{Wu}$ 's method. 


\section{Conclusions}

Aiming at the hidden property analysis problem, we developed the CBR method for hidden property analysis of a judgment debtor. We introduced the research framework of the developed method, the presentation of enforcement cases, the calculation method for case similarity, the extraction of a similar enforcement case set, and the generation of recommendations. Besides, a case study concerning hidden property analysis of a judgment debtor is provided to illustrate effectiveness of the developed method. The conclusions of our work are as follows.

Firstly, the framework of CBR-based hidden property analysis of a judgment debtor is regarded as a useful tool to assess whether the judgment debtor in the target enforcement case hides property or not. We extracted similar historical cases and used the information and knowledge of similar historical cases to provide the recommendation of hidden property analysis of the judgment debtor. The recommendation of hidden property analysis was consistent with the actual law enforcement. Thus, it can be seen that the developed method has high accuracy.

Secondly, considering the information from the inspection and control system constructed by the Supreme People's Court of China, the enforcement case's attributes are represented by crisp symbols, crisp numbers, interval numbers, and fuzzy linguistic variables, and a hybrid similarity measure between a historical enforcement case and the target enforcement case is developed. The similarity measure method is feasible and straightforward.

Thirdly, the extraction method for similar historical enforcement cases can reduce the slope of case retrieval. The extraction method extracts the five most similar historical enforcement cases out of the 15 enforcement cases selected by manual screening, which can reduce law enforcement officers' work pressure and improve efficiency of handling enforcement cases.

Fourthly, we not only search for similar historical enforcement cases but also give the optimal recommendations. Moreover, the attributes of the recommendations consider different data types and are different from the previous work.

However, many aspects need to be further improved. Firstly, due to the research conditions' limitations, the sample size of the data collected in the research process on hidden property analysis is small. We hope to further improve the research results' accuracy using a sufficiently large data sample. First, we will try nonparametric methods after testing covariability/rejection rates considering real data to make a conclusion about the quality of the results. Second, machine learning or deep learning may solve these problems well. We explore machine learning or deep learning methods to analyze whether the judgment debtor hides property or not provided that there are sufficient data. Third, there still remain many deficiencies in the quantitative presentation of some attributes, such as credibility, which need to be further improved. Fourth, the case presentation method proposed cannot meet the legal instrument description requirements, so it is necessary to study case presentation based on ontology and the method of extraction of similar case sets. Fifth, considering neutrosophic statistics have some advantages in dealing with vague, indecisive, or fuzzy sample data [43-45], we will apply neutrosophic statistics to the hidden property analysis problem.

Author Contributions: Conceptualization, Z.Z. and L.Z.; methodology, S.W.; software, S.W.; validation, Z.Z.; formal analysis, Z.Z.; investigation, S.W.; resources, S.W.; data curation, S.W.; writingoriginal draft preparation, H.Z., Z.Z. and L.Z.; writing-review and editing, H.Z. and L.Z.; visualization, L.Z.; supervision, H.Z.; project administration, H.Z.; funding acquisition, H.Z. All authors have read and agreed to the published version of the manuscript.

Funding: This work was supported by the National Social Science Foundation of China (No. 18BJY108).

Institutional Review Board Statement: Not applicable.

Informed Consent Statement: Not applicable. 
Data Availability Statement: Data sharing not applicable.

Acknowledgments: The authors are thankful to the editors and the reviewers for their comments and suggestions to improve the quality of the manuscript.

Conflicts of Interest: We declare that there are no conflicts of interest.

\section{References}

1. Bell, E. Concealing and disguising criminal property. J. Money Laund. Control. 2009, 12, 268-284. [CrossRef]

2. Dal Pozzolo, A.; Caelen, O.; Le Borgne, Y.A.; Waterschoot, S.; Bontempi, G. Learned lessons in credit card fraud detection from a practitioner perspective. Expert Syst. Appl. 2014, 41, 4915-4928. [CrossRef]

3. Van Vlasselaer, V.; Bravo, C.; Caelen, O.; Tina, E.; Leman, A.; Monique, S.; Baesens, B. APATE: A novel approach for automated credit card transaction fraud detection using network-based extensions. Decis. Support Syst. 2015, 75, 38-48. [CrossRef]

4. Dreżewski, R.; Dziuban, G.; Hernik, Ł.; Pączek, M. Comparison of data mining techniques for Money Laundering Detection Sys-tem. In Proceedings of the 2015 International Conference on Science in Information Technology (ICSITech), Yogyakarta, Indonesia, 27-28 October 2015.

5. Van Vlasselaer, V.; Eliassi-Rad, T.; Akoglu, L.; Snoeck, M.; Baesens, B. Gotcha! Network-based fraud detection for social security fraud. Manag. Sci. 2017, 63, 3090-3110. [CrossRef]

6. Carcillo, F.; Pozzolo, A.D.; Le Borgne, Y.-A.; Caelen, O.; Mazzer, Y.; Bontempi, G. SCARFF: A scalable framework for streaming credit card fraud detection with spark. Inf. Fusion 2018, 41, 182-194. [CrossRef]

7. Zhang, Z.; Lin, J.; Zhang, H.; Wu, S.; Jiang, D. Hybrid TODIM Method for Law Enforcement Possibility Evaluation of Judgment Debtor. Mathematics 2020, 8, 1806. [CrossRef]

8. Wu, S.; Lin, J.; Zhang, Z. New distance measures of hesitant fuzzy linguistic term sets. Phys. Scr. 2021, 96, 015002. [CrossRef]

9. He, J.; Zhang, H.; Zhang, Z.; Zhang, J. Probabilistic Linguistic Three-Way Multi-Attibute Decision Making for Hidden Property Evaluation of Judgment Debtor. J. Math. 2021, 2021, 9941200. [CrossRef]

10. Aamodt, A.; Plaza, E. Case-Based Reasoning: Foundational Issues, Methodological Variations, and System Approaches. AI Commun. 1994, 7, 39-59. [CrossRef]

11. Ting, S.L.; Wang, W.M.; Kwok, S.K.; Tsang, A.H.C.; Lee, W.B. RACER: Rule-Associated Case-based Reasoning for supporting General Practitioners in prescription making. Expert Syst. Appl. 2010, 37, 8079-8089. [CrossRef]

12. Zhuang, Z.Y.; Churilov, L.; Burstein, F.; Sikaris, K. Combining data mining and case-based reasoning for intelligent decision support for pathology ordering by general practitioners. Eur. J. Oper. Res. 2009, 195, 662-675. [CrossRef]

13. Wu, M.C.; Lo, Y.F.; Hsu, S.H. A fuzzy CBR technique for generating product ideas. Expert Syst. Appl. 2008, 34, 530-540. [CrossRef]

14. Araz, C.; Ozfirat, P.M.; Ozkarahan, I. An integrated multicriteria decision-making methodology for outsourcing management. Comput. Oper. Res. 2007, 34, 3738-3756. [CrossRef]

15. Wei, M.; Dai, Q. A prediction model for traffic emission based on interval-valued intuitionistic fuzzy sets and case-based reasoning theory. J. Intell. Fuzzy Syst. 2016, 31, 3039-3046. [CrossRef]

16. Zheng, J.; Wang, Y.-M.; Lin, Y.; Zhang, K. Hybrid multi-attribute case retrieval method based on intuitionistic fuzzy and evidence reasoning. J. Intell. Fuzzy Syst. 2019, 36, 271-282. [CrossRef]

17. Somi, S.; Seresht, N.G.; Fayek, A. Framework for Risk Identification of Renewable Energy Projects Using Fuzzy Case-Based Reasoning. Sustainability 2020, 12, 5231. [CrossRef]

18. Cai, H.; Zhang, X.; Zhang, Y.; Wang, Z.; Hu, B. A Case-Based Reasoning Model for Depression Based on Three-Electrode EEG Data. IEEE Trans. Affect. Comput. 2018, 11, 383-392. [CrossRef]

19. Hu, X.; Xia, B.; Skitmore, M.; Chen, Q. The application of case-based reasoning in construction management research: An overview. Autom. Constr. 2016, 72, 65-74. [CrossRef]

20. Pla, A.; López, B.; Gay, P.; Pous, C. eXiT*CBR.v2: Distributed case-based reasoning tool for medical prognosis. Decis. Support Syst. 2013, 54, 1499-1510. [CrossRef]

21. El-Fakdi, A.; Gamero, F.; Melendez, J.; Auffret, V.; Haigron, P. eXiTCDSS: A framework for a workflow-based CBR for interventional Clinical De-cision Support Systems and its application to TAVI. Expert Syst. Appl. 2014, 41, 284-294. [CrossRef]

22. Ramos-González, J.; López-Sánchez, D.; Castellanos-Garzón, J.A.; de Paz, J.F.; Corchado, J.M. A CBR framework with gradient boosting based feature selection for lung cancer subtype classification. Comput. Biol. Med. 2017, 86, 98-106. [CrossRef]

23. Herrero-Reder, I.; Urdiales, C.; Peula, J.; Sandoval, F. CBR based reactive behavior learning for the memory-prediction framework. Neurocomputing 2017, 250, 18-27. [CrossRef]

24. Gilboa, I.; Schmeidler, D. Act similarity in case-based decision theory. Econ. Theory 1997, 9, 47-61. [CrossRef]

25. Gilboa, I.; Schmeidler, D.; Wakker, P.P. Utility in Case-Based Decision Theory. J. Econ. Theory 2002, 105, 483-502. [CrossRef]

26. Gilboa, I.; Schmeidler, D. A Theory of Case-Based Decisions; Cambridge University Press (CUP): Cambridge, UK, 2001.

27. Caramuta, D.M.; Contiggiani, F.; Tohmé, F. Memory and Similarity: A Graph\# Theoretic Model for Case Based Decision Theory. In Proceedings of the XLI Meeting of the Argentina Association of Political Economy, Salta, Argentina, 28 August 2006; Argentina Association of Political Economy: Salta, Argentina, 2006.

28. Fan, Z.P.; Li, Y.H.; Wang, X.; Liu, Y. Hybrid similarity measure for case retrieval in CBR and its application to emergency response towards gas explosion. Expert Syst. Appl. 2014, 41, 2526-2534. [CrossRef] 
29. Fan, Z.P.; Li, Y.H.; Zhang, Y. Generating project risk response strategies based on CBR: A case study. Expert Syst. Appl. 2015, 42, 2870-2883. [CrossRef]

30. Zhang, Z.; Lin, J.; Miao, R.; Zhou, L. Novel distance and similarity measures on hesitant fuzzy linguistic term sets with application to pattern recognition. J. Intell. Fuzzy Syst. 2019, 37, 2981-2990. [CrossRef]

31. Zhang, Z.; Li, J.; Sun, Y.; Lin, J. Novel Distance and Similarity Measures on Hesitant Fuzzy Linguistic Term Sets and Their Ap-plication in Clustering Analysis. IEEE Access 2019, 7, 100231-100242. [CrossRef]

32. Zhang, Z.; Zhao, X.; Qin, Y.; Si, H.; Zhou, L. Interval type-2 fuzzy TOPSIS approach with utility theory for subway station operational risk evaluation. J. Ambient Intell. Humaniz. Comput. 2021, 1-15. [CrossRef]

33. Zhou, L.; Lin, J.; Li, Y.; Zhang, Z. Innovation Diffusion of Mobile Applications in Social Networks: A Multi-Agent System. Sustainability 2020, 12, 2884. [CrossRef]

34. Zhang, Z.; Zhang, H.; Zhou, L.; Li, Y. Analyzing the Coevolution of Mobile Application Diffusion and Social Network: A Multi-Agent Model. Entropy 2021, 23, 521. [CrossRef]

35. Chergui, O.; Begdouri, A.; Groux-Leclet, D. Integrating a Bayesian semantic similarity approach into CBR for knowledge reuse in Community Question Answering. Knowl. Based Syst. 2019, 185, 104919. [CrossRef]

36. Adedoyin, A.; Kapetanakis, S.; Samakovitis, G.; Petridis, M. Predicting fraud in mobile money transfer using case-based reason-ing. In Proceedings of the International Conference on Innovative Techniques and Applications of Artificial Intelligence, Cambridge, UK, 12-14 December 2017; Springer: Cham, Switzerland, 2017; pp. 325-337.

37. Boehmer, W. Analyzing Human Behavior Using Case-Based Reasoning with the Help of Forensic Questions. In Proceedings of the 24th IEEE International Conference on Advanced Information Networking and Applications, Perth, Australia, 1 June 2010; Institute of Electrical and Electronics Engineers (IEEE): Piscataway, NJ, USA; pp. 1189-1194.

38. Chang, C.C.; Hua, K.H. Applying case-based reasoning and expert systems to coastal patrol crime investigation in Tai-wan. In Proceedings of the International Conference on Intelligence and Security Informatics, Taipei, Taiwan, 17 June 2008; Springer: Berlin/Heidelberg, Germany, 2008; pp. 161-170.

39. Han, M.L.; Han, H.C.; Kang, A.R.; Kwak, B.I.; Mohaisen, A.; Kim, H.K. WHAP: Web-Hacking Profiling Using Case-Based Reasoning. In Proceedings of the 2016 IEEE Conference on Communications and Network Security (CNS), Philadelphia, PA, USA, 17-19 October 2016.

40. Guerdjikova, A. Case-based learning with different similarity functions. Games Econ. Behav. 2008, 63, 107-132. [CrossRef]

41. Shepard R, N. Toward a universal law of generalization for psychological science. Science 1987, 237, 1317-1323. [CrossRef]

42. Billot, A.; Gilboa, I.; Schmeidler, D. Axiomatization of an exponential similarity function. Math. Soc. Sci. 2008, 55, 107-115. [CrossRef]

43. Aslam, M.; Rao, G.S.; Khan, N. Single-stage and two-stage total failure-based group-sampling plans for the Weibull distribution under neutrosophic statistics. Complex Intell. Syst. 2021, 7, 1-10. [CrossRef]

44. Aslam, M. Analyzing wind power data using analysis of means under neutrosophic statistics. Soft Comput. 2021, 25, 7087-7093. [CrossRef]

45. Aslam, M.; Bantan, R.A.R.; Khan, N. Design of a New Attribute Control Chart Under Neutrosophic Statistics. Int. J. Fuzzy Syst. 2019, 21, 433-440. [CrossRef] 